\title{
The Aristotelian law of the excluded middle and the language "Pitfalls" of modern scientific pedagogical dialogue
}

\author{
Andrey V. Korzhuev - Almira R. Bayanova - Saule B. Dautova - Svetlana \\ V. Dmitrichenkova - Muslimat G. Akhmedova
}

DOI: 10.18355/XL.2022.15.01.18

\begin{abstract}
Modern dialogue in the semantic context of educational sciences plays an extremely important role as a tool for making science-based decisions as a means of assessing the efficiency of innovations proposed by various authors. However, the practice of modern scientific discussions in pedagogy reveals a lot of problems. Analysis of the research topic literature shows that the core of this problem is the failure to observe the rules of logically correct discourse by the dialogue participants. In the pedagogical dialogues, in particular, there is a simplified application of the logical law of the excluded middle introduced by Aristotle, which does not reflect the rich assortment of the educational field. It has a solid methodological basis in mathematics, in the humanities though (and in pedagogy, in particular), it is often used to analyze phenomena, objects, and scientific facts that go beyond the area of its adequate applicability. It is often used: a) for vague classification forms; b) for insufficiently and accurately defined objects; c) for pairs of events that are not opposite (in terms of probability theory) and mutually exclusive. It results in dialogues participants: a) solving the problems of choosing conceptual foundations and practical decisions for implementation in education incorrectly; b) coming to rigid, rigorous conclusions; c) unjustifiably abandoning many educational traditions, replacing them with insufficiently verified innovations. The problem is exacerbated by the fact that the participants in pedagogical dialogues lack mastery of stylistic resources, the use of which allows the inceptors of pedagogical ideas to achieve an adequate understanding of their inferences and conclusions made by other participants. These circumstances, supported by the provisions of the European researchers of education, determine the relevance of the chosen topic. The purpose of this article is: a) to find ways to conduct a logically correct pedagogical dialogue that actively uses the Aristotelian law of the excluded middle (both in a constructive format and in terms of prohibition criteria); b) to find stylistic resources of such a dialogue, combining the scientific rigor of the humanitarian logical form and stylistic aesthetic appeal. The results of the conducted research are the conclusions that an effective pedagogical dialogue using the law of the excluded middle is conditioned by: a) replacement of dichotomous, rigid forms in the logic "either - or" with a concomitant format of combination of "both the one and the other at the same time; but neither one nor the other separately"; b) appropriate stylistic tools, including: stylistic gradation, metaphor, oxymoron, and emphatic transposition. As negativity that must be overcome in every possible way, there are the "traps" of pedagogical dialogues that require constructive and prohibiting formats of the excluded middle principle: a) incorrect "play" on a high degree of uncertainty of the original defended premise; b) deliberate scientifically dishonest methods of substantiating their own conclusions, forcing opponents to recognize the correctness and validity of the dichotomous form applied to the phenomena to which it cannot be applied.
\end{abstract}

Key words: The Aristotelian law of the excluded middle, the language of scientific dialogue, linguistic representation, stylistic clichés, problems of choice, logicalsemantic explicitness of the conclusions of the dialogue initiator, tradition and innovation

XLinguae, Volume 15 Issue 1, January 2022, ISSN 1337-8384, eISSN 2453-711X 


\section{Introduction}

Today, the dialogue in the mathematical, natural-scientific, technical fields of knowledge has a sufficient degree of logical-content and stylistic formalization. It is conventionalized by scientists in terms of a glossary and methods of substantiating conclusions and statements of reason. The same cannot be said about dialogue in scientific and practical pedagogy. Observations and analysis of records of past oncescientific dialogues in the community of scientists from the field of educational sciences show that often each of the participants speaks about their own vision, almost completely ignoring the questions, doubts, objections, and clarifications of the dialogue partners, and responds inadequately to the challenges of the dialogue adherents.

Among the many components of logic that are incorrectly used in dialogues, we especially highlight the problem of analyzing opposite events (in terms of probability theory), facts, solutions to pedagogical problems, and all this can be combined with the cliché "logical law of the excluded middle." In the dialogues evolving in the pedagogical field, it is manifested in those cases when the participants in the dialogues have to make a choice: a) between two differing conceptual solutions to relevant problems of education; b) between two technological approaches to the implementation of these solutions; c) between the two methods necessary for assessing specific skills that students developed. In our opinion, the main negative consequence of all of the above mentioned is the widely observed solution of the problem of choice by educational scientists and educational practitioners following the dichotomous logic of "either - or". Stylistically, this negative is reflected in such binary forms as: a) traditional or innovative teaching; b) objective or abstractfigurative visibility; c) training focused either on theoretical knowledge or practical skills, and a number of others. The inability to correctly apply the law of the excluded middle often leads to a hurricane-like implementation of innovative approaches and technologies in the practice of teaching and education. On the one hand, it leads to a considerable truncation of traditional concepts that proved to have positive value, and on the other - to the reduction of the applied educational attributes arising from them. It is largely due to the fact that the scientific and practical pedagogical dialogues preceding practical steps represent a plethora of participants' opinions and judgments that do not align well with each other. They do not allow expressing the result of the discussion both briefly, in keywords, and at the same time diversely in terms of the meaning or message the initiator of the dialogue wanted to convey.

At the same time, today's pedagogy is characterized by the vagueness of definitions of basic concepts and categories; it has not yet mastered logically correct methods of classification and determination of the completeness of the content fields division. There are many other logical nuances that are not specific to the STEM disciplines. Therefore, a competent scientific dialogue in the science of education is extremely necessary today (Sabirov et al., 2015). In the process of such a dialogue between scientists and educational practitioners, there should be developed well-considered and worded judgment-based positions, allowing to generate deeply meaningful solutions to many problems that are relevant for teaching and educating the young generation. For our research, these are, first of all, solutions that would competently reflect the dialectic of the relationship between tradition and innovation - so that pedagogical science can meet the innovative challenges of society (1) and at the same time preserve the experience gained by many generations of scientists and practitioners (2).

These considerations determined the formulation of the problematic field of the article: a) what features of the educational field reflect the law of the excluded middle and what are the correct logical attributes arising from all this; b) what are the regulators of the scientific dialogue that solves the problem of choosing conceptual 
solutions and methodological tools in the field of educational theory and practice; c) what stylistic devices could be used to ensure correct application of the law of the excluded middle to facilitate effective communication between scientists-educators so that they could "hear" each other in the process of dialogue. In this regard, the purpose of the article is: a) to investigate, search for and condense the key methods of logically correct design of the pedagogical dialogue, requiring the law of the excluded middle (both in a constructive format and following the logic of the prohibition criteria), and b) to search for stylistic resources of a pedagogical dialogue focused on the law of the excluded middle, which would show to all participants the explicitness of the meanings and logic of reasoning of the problems discussed by dialogue initiators.

\section{Literature Review}

We will begin this section with a statement that the reason for the difficulties in organizing a correct pedagogical dialogue is a set of methodological problems that have not yet been resolved in relation to the sciences of education. Thus, the problematic nature of the scientific status of pedagogy and its textual presentation is confirmed by the works of the European scientists: H.J. Koskinen (2018), D. Pritchard (2013), H. Kallio, K. Virta, and M. Kallio (2018), R.H. Ennis (2018), F. Zenker (2018), and a number of other authors. On the one hand, the papers written by the above mentioned scientists emphasize the specificity of the subject of pedagogy, its essential difference from the objects of mathematics, technical, and natural sciences and the resulting impossibility of forming the structure and content of pedagogical theory on the model of STEM disciplines. On the other hand, the authors note the urgent need to systematize the vast array of empirical data accumulated during educational practice, as well as ideas, approaches, concepts, theoretical schemes and subject-practical knowledge, which is being introduced into pedagogy from the areas that are not attributed by scientists to the scientific field (Razumovskaya et al., 2018). All these determine the difficulties of adequate linguistic display of pedagogical knowledge and methods of obtaining it: "confusing pedagogy stounding in its logical lack of accuracy" (Snaza, 2018; Letiche, 2017) produces the same hard-to-interpret stylistic constructions.

Methodological problems of educational sciences are also discussed in the works of S.H. Billig and A.S. Waterman (2014), T.S. Shirish (2013), and A.A. Hanan (2016). They are mainly about the methods of stylistic display of objects and phenomena in the sphere of education, as well as the resources of stylistics of pedagogical laws with the emphasis on the possibility of implementing everything described as it is done in mathematics and other STEM disciplines. However, concluding that it is impossible, the authors do not offer specific guidelines for the formation of the scientific apparatus and tools for pedagogy. Problems of scientific display and description of educational reality, construction of the content of pedagogical concepts and categories, construction of stylistic clichés in pedagogy, educational psychology, sociology are discussed in the works of P.A. Alexander (2017), B.J. Barczynski, and R.M. Kalina (2015), M.B. Baxter Magolda (2004), L. Tomasz (2017), M. Koivuniemi, H. Järvenoja and S. Järvelä (2018). The problem of displaying the content and logic of constructing pedagogical concepts in the reflection of the category of understanding is discussed in the articles by P.A. Alexander (2017), V. Rodek (2019), A.A. Kornienko (2015), C. Rapanta (2018; 2019), M. Kim and I.A. Wilkinson (2019), N. Mashkin et al. (2021) - this is very important for the scientific dialogue discussed in the article. With all the clearly striking differences in the original author's interpretations of the concept of "understanding," the cited scientists agree that in modern pedagogical science, the semantic interpretations of many concepts, both basic and "derived," are polyphonic. Stylistically identically

XLinguae, Volume 15 Issue 1, January 2022, ISSN 1337-8384, eISSN 2453-711X 
designated concepts, patterns, research approaches, which are used to obtain them, have different meanings and content in different sources. A lot of extra-educational concepts, principles, categories receive interpretations and representations that seriously contradict those offered in encyclopedic primary sources.

For the problem of scientific dialogue analyzed in our article, it is important that many European authors like P.A. Alexander (2017), M.B. Baxter Magolda (2004), C. Coney (2014), A.A. Hanan (2016), discuss the stylistics of pedagogical works, the peculiarities of the linguistic reflection in them of meanings and the logic of obtaining scientific knowledge, call it "critical pedagogy" (sometimes synonymous with "reflexive pedagogy"). These authors correlate pedagogical regularities and concepts with basic philosophical categories, analyze in detail the genealogical, ontological, and historical aspects of the formation of a glossary and the scientific logic of education, offer and substantiate the author's versions of filling the scientific attributes of the educational sphere. The above-mentioned philosophical layer of scientific-educational content is also analyzed in the works of H.J. Koskinen (2018), W. Brezinka (2012). We consider it important to add to the mentioned research works a number of texts projecting the scientific content of the educational sphere into an epistemic format. In the works of B.J. Barczyński and R.M. Kalina (2015), G. Gardiner (2015), M. Chekour, M. Laafou, and R. Janati-Idrissi (2018), the problem of building scientific attributes of pedagogy is focused in the cliché "theoretical norm of pedagogical knowledge." In these works, attempts are also made to find methodologically verified approaches to the construction of pedagogical definitions, concepts, and theoretical constructions. Particular and applied aspects of the glossary of pedagogy are discussed in the work of C. Coney (2014), dedicated to the scientific apparatus of comparative pedagogy, as well as in the article by C. Rapanta and F. Macagno (2019), devoted to the problem of multi-aspect reflection of the content fields of pedagogical terms.

In their books and articles, all the authors mentioned argue that pedagogy, which is subject to the terminological and meaningful expansion of various areas of knowledge and practice, today does not have scientifically verified tools for obtaining and confirming (refuting) its results. Therefore, we consider it possible to say that the above review of sources leads to the conclusion about the need for epistemological intervention in the problem of scientific reflection of pedagogical knowledge and, in particular, its dialogue domain.

A significant methodological component of the topic addressed in the article determines the reference made to the texts of other scholars of science, among which it is interesting to consider the scientific dialogue of N. Snaza (2018) and H. Letiche (2017). The titles and contents of two articles testify to the unattractiveness of the scientific "portrait" of pedagogy: in H. Letiche (2017), "indistinct pedagogy" (the first adjective can be synonymous with "difficult to comprehend...", "amazingly intricate pedagogy... ". Aspects directly related to the problem of choice in the field of education, as well as the relationship between tradition and innovation, are discussed in the works (Koskinen, 2018; Zenker, 2018; Hanan, 2016; Tomasz, 2017; Tannen, 1999). The arguments proposed by the authors appertain to the problem we are examining and from all perspectives reflect the law of the excluded middle - both in a constructive and in a prohibitive format. These two segments, according to the authors, require further research. The analysis of the content of these texts explicates the conclusions of scientists about the relevance of the development of a topic related to the competent application of the law of the excluded middle in scientific dialogue in the pedagogical sphere.

This review can be continued with an analysis of works devoted specifically to scientific dialogue in the humanitarian fields of knowledge. The topic of the pedagogical scientific dialogue is linked with attempts to analyze pedagogical discourse and its interpretations in works written at the turn of the $20^{\text {th }}$ and $21^{\text {st }}$ 
centuries (Gumperz, 1982; Halliday, 2006; Stubbs, 2007; Searle, 2004; Brown, 1995). Topics related to argumentation in the pedagogical scientific field are also devoted to the works (Tannen, 1999; Goodman \& Goodman, 2013). The relevance of the study of topics related to dialogue in the pedagogical scientific field is also evidenced by modern works: D. Skidmore and K. Murakami (2016), T. Bridgeford, K.S. Kitalong and R. Selfe (2004), D. Rose (2014), N. Mercer, R. Wegerif \& L. Major (2019), L. Major et al. (2018). The works of A.N. Tariqan (2012), C. Rapanta (2019), N. Irawan, and T.F. Valentina (2021) are devoted to the relevance of the development of problems of the correctness of various types of argumentation in pedagogical research. Discussing various features of justifications made by scientific dialogues participants addressing their own conclusions in the social and humanitarian sphere, and especially in educational theory and practice, the authors practically unanimously argue that the search for subtle logical forms of correct dialogue is still an urgent research task. Such forms, as shown by the preliminary consideration in the previous section of the article, include the law of the excluded middle - both from the point of view of the possibilities of constructive application and in the context of the prohibition criteria.

All these conclusions predetermined our research topic focused on the problem of the logic of the excluded middle as a resource for competent dialogue in the Humanities. It is certainly focused on the topic of substantiating stylistic resources that can make a scientific dialogue on the problems of choice in the process of designing education sensible and perceivable by the participants in the dialogues adequately fitting to the meanings transmitted by the dialogue initiators.

\section{Results}

\section{The Logical Resources of the Pedagogical Dialogue Associated with the Law of the Excluded Middle, and Their Stylistic Representation}

It is difficult to conduct a pedagogical scientific dialogue for a number of reasons. These reasons include the difficulty and ambiguity of the manifestation of a logical form in the fields of humanitarian knowledge. It is attributable to the fact that when obtaining this knowledge, scientific approaches coexist with subject-based practical methods and strategies of activity. All of the above is fully applicable to the law of the excluded middle and the peculiarities of its use in the process of putting forward by the participant of the dialogue their own conclusions and inferences, as well as in the process of refuting, supplementing, and clarifying the statements of the partners in the dialogue. As part of our investigation, the following formulation of the law under discussion will be appropriate and understandable: in a certain conclusion, judgment, statement, either an affirmative form (this is true) or a negative one (this is not true) is permissible, and there is no third possibility.

We refer to this law because of the criticism that has been heard against it from philosophers and logicians since the most ancient times. For example, Aristotle expressed doubts about the applicability of this law to events of a possible future. G. Hegel ironically spoke about meaningless statements in the logic of the excluded middle. However, the objection of L. Brouwer, who pointed out that logical laws have significantly different coloring when applied to objects of different nature, is especially relevant, and the main thing is that in many cases, there is a third possibility between a statement and its negation (Ivin, 2019: 145). L. Bauer emphasized in every possible way that it cannot be excluded, and above all, for infinite sets of objects: a) if the set is finite, all its components can be enumerated, counted, and to be precise, for example, whether there is an object in this set with properties of interest to the author, or it is not; b) if the set is infinite, then neither the statement about the existence of an object with the properties of interest to the researcher, nor its refutation are true.

XLinguae, Volume 15 Issue 1, January 2022, ISSN 1337-8384, eISSN 2453-711X 
We continue this idea with the "classification traps" that are often encountered in pedagogy. These are situations in which, for various (quite forgivable) reasons, it is impossible to confidently assert that the components identified during the classification of a set: a) during the "summation" are equal in volume to the divided field (completeness criterion); b) do not intersect with each other. In this case, it is often very difficult to determine: a) for example, to which of the two subdivisions of the educational field the interesting for scientist object (phenomenon) belongs; b) whether all objects (phenomena) of the shared field will find their classification category; c) is it possible to supplement the previously found classification based on discovering an object (phenomenon) of education, which is difficult to attribute to any initially identified component (part of the divisible field). For example, the law of the excluded middle, in connection with the first consideration, problematizes the question: does the teaching method, which is interesting to the author, belong to visual or not (since it is not exclusively focused on visualization, but includes other characteristics - attributable to the other two components of dividing the field of teaching methods: verbal and practical methods). The second and third considerations problematize the answer to the question: to which of the triad of the well-known methods, distinguished based on the "method of transmitting information to the student," can the case study method be related to, and which type of method excludes it. It is problematic to provide a definite, precise answer here - it is very difficult to unambiguously attribute this method to one of the known types (verbal, visual, practical), just as it is difficult to choose from the three presented such a type of training that confidently excludes case study.

The most "relevant" questions similar to those given above in the context of the law of the excluded middle arise in a case of dichotomous division when the entire investigated field is divided into two parts: objects in the first case have a feature of interest to the researcher, though it is absent in the second one. With the exception of trivial cases (whether pedagogical violence is humane or not, permissible or not (Snaza, 2018); if the students are male or female (Letiche, 2017); whether developmental learning is positively valuable or not (Koskinen, 2018), it is also problematic to follow this type of division. For all the seeming simplicity and clarity of the law of the excluded middle, logicians and philosophers consider it overly rigid and rigorous, and this is especially clearly manifested in the humanities of the weak epistemological version.

Here we go beyond the framework of classifications and, in the context of discussing the law of the excluded middle, we consider the dichotomous division of this or that educational field through several polar forms: positively valuable - negative; personally significant - personally destructive; evidence-based training - dogmatic training; new and progressive in education - outdated, from which it is necessary to rebuild. For example, in relation to the topic of digitalization of education, which is widely discussed today, such a dichotomous division turns into a dialogue of traditions and innovations, new and outdated. At the same time, if we adhere to the framework of the discussion of the applicability of the law of the excluded middle, we will try to illustrate the unproductiveness of numerous extreme, rigid points of view that polarize the educational environment into two "camps": adherents and opponents of digital learning.

Today, it is obvious that digitalization is a modern trend at school and university education and a topic that causes a wide variety of scientific and scientific-practical discussions. Digitalization involves the introduction into the educational process of various computer training programs, electronic textbooks, online workshops, the work of schoolchildren and students in digital environments. What is important for the dialogue? The digitalization of education is predetermined by the digitalization of the economy and other spheres of life - with this, the adherents of this idea substantiate the need to integrate students into the digital world as early as possible. As an 
objectionable argument, an opponent of the adherent of the education digitalization can provide the considerations given in the book of the German scientist and sociologist M. Spitzer (2014).

It is essential to highlight the following counterarguments, among others cited by the author: physiologists have confidently established that knowledge obtained exclusively at the computer is weaker and slower "imprinted" in the brain than the knowledge that can be acquired through touching some objects with hands (Spitzer, 2014). For example, the knowledge of anatomy among students of a medical university turns out to be much more solid and in demand in the study of specialized clinical disciplines when "contact" forms of work are used in the educational process (work with corpses in anatomical theater, dissection, etc.). This knowledge is less solid when natural contact is replaced by computer screen atlases of various human organs and systems and other digital dummies and imitators (Akhmadieva et al., 2021). It is advisable to supplement this empirical refutation of the opinion about the exceptional positivity of digital education of doctors (based on a survey of samples of senior medical students) with a theoretical refutation. M. Spitzer (2014) has data that by means of the multichannel encephalography method, there was recorded activation of the motor zones of the frontal lobes of the students' brain, with a predominance of "subject," contact learning. For students with a sharp predominance of digital content, this activation occurred much later (Spitzer, 2014). This gives reason to believe that the digital way of comprehending the world around them negatively affects the development of students' brains reduces the pace of their mental development.

The viewpoint of the digital education adherent can be theoretically refuted by a dialogue partner through applying some data provided in M. Spitzer's (2014) book. The author, in particular, notes that "modern neurobiological studies using functional magnetic resonance imaging have shown that the recognition by schoolchildren of the native language letters that they learn by handwriting also leads to the activation of the motor regions of the brain cortex. In the event that the letters were mastered by entering through the computer keyboard, the described activation did not occur (or it came much later). Neuroscientists have also found that the formation of an image of letters in the mind of a schoolchild by means of a pen and a pencil creates "motor memory traces" (Spitzer, 2014), which, during the perception of letters, are activated and make it easier for the student to recognize these letters by their visual image" (Spitzer, 2014: 134).

Long-term empirical research based on representative samples of students and theoretical refutation of the digital learning effectiveness is complemented by dialogue participants addressing scientific authorities (a combination of three types of argumentation). This allows the participant of the dialogue to refute the exceptional and unequivocal positivity of digital learning and its advantage over traditional (object-natural) learning. The end of this refutation is as follows: direct personal contact as a way of learning is superior to indirect contact through a computer display (Spitzer, 2014: 135). The law of the excluded middle transforms this conclusion: "innovative digital education - traditional object-natural education" dyad considered in scientific dialogues can not be solved through a rigid, rigorous format. Therefore, in the dialogue, it is necessary to search for a combined format of educational tradition and innovation. It requires a balanced, scrupulous identification of the merits and demerits of the solutions and technologies proposed by the "digital education" adherents for their implementation in the teaching practice.

A logically correct scientific dialogue in educational science, based on competent, dialectical use of the law of the excluded middle, necessarily presupposes a final analysis, the result of the conducted discussion. The methodological requirements in this case are as follows: a distinct logical arrangement of the pedagogical scientific

XLinguae, Volume 15 Issue 1, January 2022, ISSN 1337-8384, eISSN 2453-711X 
discourse, the explicitness of its logical-semantic structure. Here are some typical examples:

- the initial statement of the dialogue initiators received a detailed and multifaceted justification, however, the relevant pedagogical problem associated with it remained outside the scope of participants' consideration. After the disclosure of the digital negative presented to the dialogue partners, the initiators of this idea ignored the topic of combining digital and traditional (object-natural) learning. Stylistic cliché, appropriate in this case: meaningful incompleteness of the dialogue;

- a number of used arguments supporting negative attitudes to digital education refer to empirical refutations of the conclusions made by the digitalization adherents. However, at the same time, the representativeness of the samples, on the basis of which there was conducted the experimental survey, raises doubts since ... (possible reasons are given). In this regard, the above arguments do not give grounds to accept the idea of digital educational negativity. In future dialogues, it is desirable to confirm the early empirical arguments theoretically, addressing the physiological and psychological mechanisms of the observed phenomena of the educational field (examples are given in this section above). Stylistic clichés reflect the following situation: insufficient theoretical substantiation of the conclusions, which does not allow considering the author's point of view as confirmed; one of the two competing points of view is confirmed better (worse) than the other, the polar opposite.

- insufficiently convincing arguments given by the participants in the dialogue who defended the idea of a negative attitude to digital education did not allow opponents (adherents of digital education) to justify their point of view (Cherdymova et al., 2018). This led to an erroneous final conclusion about the exceptional positive value of digitalization and the need to dissociate from object-based learning. Stylistic clichés appropriate to this case may be as follows: extremely insufficient logical justification of the conclusion; delusive simplicity.

The above and similar stylistic forms of the final part of the dialogues allow participants and external observers to realize that along with the opposites reflected in the law of the excluded middle; there are also opposites at the level of the possibility of coexistence or mutual transition. They imply the dissociation of the participants in pedagogical dialogues from a rigid, rigorous dichotomy, the transformation of the binary logic of the "either - or" format into a dialectical one: "both the one and the other at the same time". In a number of cases, examples from the pedagogical field are used to illustrate a more complex case expressed by the formula: for two phenomena that seem to be opposites, "both the one and the other at the same time (1), but neither one nor the other separately (2)" is relevant and true. In our case, this means that neither digitalization nor object-based learning separately are able to provide a high-quality modern educational result for a schoolchild or a student. Such a result is provided only by the combined format of object-natural and digital learning, verified in the process of scientific and scientific-practical dialogues, of course, varying when moving from one specialty and training profile to another.

\section{Stylistic Resources of a Correct Dialogue in Pedagogy, Reflecting the Magnitude of Features of the Manifestation of the Law of the Excluded Middle}

Such a dialogue contemplates a set of special stylistic devices arising from the wellknown model of a dialogue by M. Stubbs (2007) (model of expectations). As applied to scientific dialogue in pedagogy, this model assumes that the initiator of this or that idea chooses such methods of stylistic design of their statements and conclusions (or refutations of the partners' conclusions) that will lead to the expected effect. More specifically, the participants in the dialogue, listening to the proposed conclusions, perceive their content and meaning adequately to the intention of the author who nominated them. Moreover, the degree of this adequacy can be predicted by this author in advance with good accuracy. It is reflected through the following fragments 
of his inner speech: presumably, the participants will adequately comprehend the statement I propose (1); the proposed method of reasoning will be difficult for a significant part of the participants in the dialogue, and therefore it must be accompanied by ... (such and such a technique) (2); the proposed example in the future dialogue should be supplemented with ... (such and such content) (3).

It allows us to move on to discussing the stylistic resources of a scientific dialogue in pedagogy directly related to the law of the excluded middle. These resources include a technique called gradation in stylistics - it is a stylistic figure that uses a gradual, phased "deployment" by the initiator of the main or core idea that he would like to convey to his opponents-participants in the dialogue. In more specific terms, in the overwhelming majority of cases, these are: giving arguments in favor of one of two competing conceptual solutions, techniques, technologies (1); a similar "defensive move" in favor of the second, seemingly opposite idea (2) and then the repetition of these stages, at the end of which the participants in the dialogue formulate a competent, balanced, in most cases combined position. If, as an example of such a concept, we take the idea presented and described above that "direct" contact with reality in the educational process is more effective than mediated through a computer display, then the phased "unfolding" of this idea will also be found by the participant in the dialogue in the book by M. Spitzer (2014). Repeatedly returning to the problem of "digital negativity" in teaching, the initiator of the dialogue can supplement everything said in the previous section of the article with the following consideration: a student or schoolchildren "transfer" excessive enthusiasm for digital content in teaching outside the educational process. At the same time, the following facts have been experimentally confirmed:

- excessive enthusiasm for digital tools reduces the ability of a pupil or student to empathize; it excessively narrows social contacts, reducing them to communication "through the display." Therefore, "digital hobby" dulls the digital student's ability to turn the mind to and to immerse into the cognitive and social world of another person and, ultimately, dulls the ability to understand him;

- excessive enthusiasm for digital learning, being transferred and practiced outside the educational process, activates a multitasking mode of a student. For example, reference to and usage of several sources of information simultaneously, quick and shallow acknowledgment with the information from various sites or portals without detailed and profound reading. It significantly reduces student's ability for solid, insightful thinking, reflection, and critical analysis of information;

- a digital student (representative of the generation $\mathrm{Z}$ ) disaccustoms him- or herself of memorizing important facts (transferring this function to the computer), he or she is unable to process the information read from the screen. The digital student does not go through the hermeneutic circle (when a certain whole is cognized through the details and connections between them, and then the result of such a dismemberment of the whole is synthesized again, "ascent to the whole"). The digital student carries out mainly horizontal, shallow search for facts does not follow the vertical primal search targeting the depth of the read (Spitzer, 2014).

Such "unfolding" repetitions allow the initiator of the dialogue to bring listeners and opponents back to the same thought several times: an excessive fascination with digital content is destructive for learning and developing personality. At the same time, the above arguments are productively "superimposed" on each other, strengthening the participants' minds in the dialogue (perhaps, initially harshly opposing its initiator) the conclusion about the extreme ambiguity of the seemingly extremely progressive idea of education digitalization.

At the same time or after the exhaustion of the argumentation resource in favor of the "digital negative", the debaters address the aspects of the positive value of digital

XLinguae, Volume 15 Issue 1, January 2022, ISSN 1337-8384, eISSN 2453-711X 
education, and as a rule, formulate a balanced position as a result of the discussion, reflecting the combined format of the "digital" with the object-based learning.

The method of gradation described by us is not limited to the field of stylistic resources of scientific dialogue in pedagogy, which uses the law of the excluded middle. We place particular emphasis on the metaphor among the devices well-known in the theoretical stylistics. With regard to the idea of digitalization of education discussed above, examples of metaphors can be the following: digital native; indigenous to the digital society; a person who was born in the digital age, the youth of generation $\mathrm{Z}$. In the dialogue evolving in the field of education, detailed metaphors, sentences or larger text fragments are also relevant. For example, a quote from the work of D. Hilbert: "prohibiting mathematicians from using the law of the excluded middle is like prohibiting boxers from using fists and gloves, and taking away a telescope from astronomers" (Ivin, 2019). The law of the excluded middle is also well illustrated by such metaphorical phrases: "inverted class": myth or reality?"; "exploratory learning: dusk or dawn?"; "Problem-heuristic education: fruit or sprout?" As well as such a metaphor: "in the world of the living matter it is difficult to draw dividing lines," illustrating the problems of applying the law of the excluded middle in an unclear classification field. Using voluble, figurative language, the initiator of the dialogue brings home to the listeners the metaphoric narrative of science, enlivening the dialogue, activating the attention of its participants in stylistically attractive ways. At the same time, the metaphorical ending of the dialogue using the law of the excluded middle is as follows: the participants in the dialogue should not always and everywhere "test harmony with the help of algebra," trying to choose one of the two and always excluding the third.

Another stylistic resource that is close to a metaphor is the method of manifesting the law of the excluded middle, which is an oxymoron. Examples of an oxymoron in relation to a negative attitude to digital education are such phrases as "desperate progress," "killer progress," "up the down staircase." They reflect the dialectic of essence and phenomenon, visible and real: a seemingly extremely progressive idea in a real-case scenario turns out to expose its negative side. Among the effective stylistic resources of scientific dialogue in pedagogy, we also single out emphatic transposition (a positively oriented statement is used in a negative sense). For our consideration, such a stylistic form can become an example of it: the results of general digitalization are very disappointing, it turns out that the new is better than the old only because of its novelty.

The described stylistic devices allow the initiator of the dialogue to create for the participants a specific-figurative basis of the abstract and generalized forms used, reflect concisely and specifically the results of the reasoning and inferences carried out, form the dialogue participants' skills in condensing key conclusions in the 'stans pede in uno' format (standing on one leg - Latin).

\section{Discussion}

Effective scientific pedagogical dialogue in line with the law of the excluded middle is not limited to everything described in the previous section of the article. We include the phenomenon clichéd as "traps of pedagogical dialogue" in the scope of the investigated content. To a large extent, these are logically and substantively dishonest ways of conducting a discussion, allowing its initiator to artificially push the opponent into a corner, to impose his or her own point of view on him or her. Such traps include stylistic or content inaccuracy and semantic ambiguity of the initial statement. For example, the statement "digitalization is the main path for the development of modern education" is too broad and hardly suitable as a topic for dialogue. In this case, it is necessary to clarify what is proposed to be understood as digitalization. Training with segmental use of computers in different functions, teaching schoolchildren or students to program or just get basic skills of a computer user, working with students in a 
virtual environment, or something else. Such specification and concretizing will allow the participants in the dialogue to competently navigate the scientific discussion, bring the problem into the format of didactics, and try to determine the conditions for the productive use of digital content in teaching.

Another trap of the dialogue is the deliberate violation of its logical correctness by the initiator when identifying the connection between the initial positions and their consequences, for example, the "reversal" of the statement. Let us clarify this with one deliberately simplified example. Let the hypothetical initiator of the dialogue try to substantiate the statement "heuristic learning is a technology unpromising for modern university education" and in the process of discussion flip around: "all unpromising technologies are reduced to heuristic learning." It is obvious that such a "turnaround" of the statement is absolutely inappropriate.

Another dialogue trap associated with the law of the excluded middle is equivocation - this is a violation of the unambiguity requirement. More specifically, it sounds like this: the choice between two opposite positions is possible if they are correctly defined. However, almost all basic terms and categories of pedagogy are ambiguous and require identifying the angle of approach in the scientific dialogue, which inevitably reduces the entire range of meanings to any specific segment. However, in the process of dialogue, there occurs either the addition to the originally chosen viewpoint and the content field of the term participating in the discussion, or an alteration of its original frame, either intentionally or accidentally. As an example, let us cite the transition from considering education as a pedagogical interaction to education as a service. Naturally, it is practically impossible to achieve any clearly defined, stated result in such a dialogue. At the same time, it would be wrong to completely dissociate from the displaying in the scientific dialogue several possible content definitions of the original term, object, or educational phenomenon. In this case, finding a delicate balance or fine line between correct and incorrect is a very difficult task.

Here we should also mention the psychological pressure of some participants on others, sometimes used in pedagogical dialogues, in order to forcefully impose their point of view on opponents. In the context of the law of the excluded middle, these are emotional addressing to partners, such as: "You forgot that in our case only one of the two is possible - a third is not given". At the same time, the truly discussed problem does not obey this harsh interpretation.

The entire complex of problems listed in this section is subject to investigation by the researchers.

\section{Conclusion}

Finally, we consider it possible to draw a number of conclusions:

- the movement of the modern scientific community of teachers towards a productive dialogue requires compliance with a logical form that is elusive in humanitarian knowledge, associated with the law of the excluded middle. At the same time, for dialogue in scientific pedagogy, in contrast to the dichotomy "either - or", the dialectical logical form is most acceptable as a physical analog (wave-particle dualism of light and matter). Its essence is that for two discussed concepts, methods, or technologies that seem to be incompatible, the formula "both the one and the other at the same time; but neither of the two separately" is the most relevant and appropriate. It is this logical reversal that makes it possible to formulate competent, verified, balanced combined solutions to many problems associated with choosing and finding the optimum;

- stylistic gradation, metaphor, oxymoron, emphatic transposition are constructive for the scientific pedagogical dialogue, involving the law of the excluded middle and its humanitarian attributes. It is predetermined by the opportunity to activate the

XLinguae, Volume 15 Issue 1, January 2022, ISSN 1337-8384, eISSN 2453-711X 
participants' attention, to construct a specific-figurative basis of abstract forms, to realize the acuteness and specificity of the discussed problems, to form the dialogue participants' ability to express their conclusions in the 'stans pede in uno' format (standing on one leg - Latin) - succinctly, explicitly and as clear as possible for opponents;

- for a constructive scientific pedagogical dialogue in the format of the law of the excluded middle, it is very important that the participants comply with the requirement, clichéd as "holding off from the traps of dialogue," including a) deliberate or accidental dishonest "play" with an insufficiently clearly defined or inaccurately foreshortened term; b) changing the angle or perspective of consideration of the basic phenomenon in the process of dialogue, its unlawful truncation or addition to those that were not included in the initial segment; c) the psychological pressure of one of the discussants on other participants in the dialogue, persuading them to use simplified dichotomous forms in a meaningfully and logically complex humanitarian field.

\section{Acknowledgments}

This paper has been supported by the Kazan Federal University Strategic Academic Leadership Program.

\section{Bibliographic references}

Akhmadieva, R.S., Mikhaylovsky, M.N., Simonova, M.M., Nizamutdinova, S.M., Prokopyev, A.I., \& Ostanina, S.S. (2021). Public relations in organizations in sportsman students view: Development of management tools or healthy and friendly relations formation. Journal of Human Sport and Exercise 16(3), 1272-1279. ISSN: 19885202.

Alexander, P.A. (2017). Reflection and Reflexivity in Practice. Versus in Theory: Challenges of Conceptualization, Complexity, and Competence. Educational Psychologist 25(4), 307-314. ISSN: 0046-1520.

Barczyński, B.J., \& Kalina, R.M. (2015). Science of Martial Arts - Example of the Dilemma in Classifying New Interdisciplinary Sciences in the Global Systems of the Science Evaluation and the Social Consequences of Courageous Decisions. Procedia Manufacturing 3, 1203-1210. ISSN: 2351-9789.

Baxter Magolda, M.B. (2004). Evolution of a Constructivist Conceptualization of Epistemological Reflection. Educational Psychologist 39(1), 31-42. ISSN 0046-1520.

Billig, S.H., \& Waterman, A.S. (2014). Studying Service-Learning: Innovations in Education Research Methodology. New York: Routledge. ISBN 978-0-203-34154-4.

Brezinka, W. (2012). Philosophy of Educational Knowledge: An Introduction to the Foundations of Science of Education, Philosophy of Education and Practical Pedagogics. Berlin: Springer Science \& Business Media. ISSN: 1932-4502.

Bridgeford, T., Kitalong, K.S., \& Selfe, R. (2004). Innovative Approaches to Teaching Technical Communication by Selfe. Utah: Utah State University Press. ISBN 0-87421-574-9.

Brown, G. 1995. Speakers, Listeners, and Communication: Explorations in Discourse Analysis. Cambridge: Cambridge Univ. Press. ISBN: 0-521-48157-0.

Chekour, M., Laafou, M. \& Janati-Idrissi, R. (2018). What are the Adequate Pedagogical Approaches for Teaching Scientific Disciplines? Physics as a Case Study. Journal of Educational and Social Research 8(2), 141-148. ISSN: 2239978X, 22400524.

Cherdymova, E.I., Vorobyeva, K.I., Romashkova, O.V., Mashkin, N.A., Grigoriev, S.M., Romanchenko, L.N., Karpenko, M.A., \& Bayanova, A.R. (2018). Photo Exhibition Influence on Student Environmental Consciousness Formation. Ekoloji 27(106), 1271-1278. ISSN: 1300-1361. 
Coney, C.L. (2014). Critical Thinking in its Contexts and in Itself. Educational Philosophy and Theory 47(5), pp. 515-528. ISSN 0013-1857.

Ennis, R.H. (2018). Critical Thinking Across the Curriculum: A Vision. Topoi 37(1), 165-184. ISSN 1572-8749.

Gardiner, G. (2015). Teleologies and the Methodology of Epistemology. Epistemic Evaluation: Purposeful Epistemology. Oxford: Oxford University Press. ISBN-13: 9780199642632.

Goodman, K.S., \& Goodman, Y.M. (2013). Making sense of learners making sense of written language. New York: Routledge. ISBN 9780203366929.

Gumperz, J.J. (1982). Discourse strategies. Cambridge: Cambridge University Press. ISBN: 9780511611834.

Halliday, M.A.K. (2006). Linguistic Studies of Text and Discourse. London: A\&C Black. ISBN: 0826488234, 9780826488237.

Hanan, A.A. (2016). What is critical about critical pedagogy? Conflicting conceptions of criticism in the curriculum. Educational Philosophy and Theory 50(10), 903-916. ISSN 0013-1857.

Irawan, N., \& Valentina, T.F. (2021). The Language of Argumentation: A Book Review. Journal of Language and Education 7(2), 274-276. DOI: https://doi.org/10.17323/jle.2021.12538.

Ivin, A.A. (2019). Logika. Moscow: Urait. ISBN 978-5-534-07467-3.

Kallio, H., Virta, K., \& Kallio, M. (2018). Modelling the Components of Metacognitive Awareness. International Journal of Educational Psychology 7(2), 94122. ISSN: 20143591.

Kim, M., \& Wilkinson, I.A. (2019). What is dialogic teaching? Constructing, deconstructing, and reconstructing a pedagogy of classroom talk. Learning, Culture and Social Interaction 21, 70-86. SSN: 2210657X, 22106561.

Koivuniemi, M., Järvenoja, H., \& Järvelä, S. (2018). Teacher education students' strategic activities in challenging collaborative learning situations. Learning, Culture and Social Interaction 19, 109-123. ISSN: 2210657X, 22106561.

Kornienko, A.A. (2015). The Concept of Knowledge Society in the Ontology of Modern Society. Procedia - Social and Behavioral Sciences 166, 378-386. ISSN: 2349-5677.

Koskinen, H.J. (2018). Antecedent Recognition: Some Problematic Educational Implications of the Very Notion. Journal of Philosophy of Education 52(1), 178-190. ISSN: 2658-6762.

Letiche, H. (2017). Bewildering pedagogy. Journal of Curriculum and Pedagogy 14, 236-255. ISSN: 15505170, 21568154.

Major, L., Brugha, M., Froehlig, C., Walker, S., Higham, R., \& Vrikki, M.A. (2018). A Dialogue about Educational Dialogue: Reflections on the Field and the Work of the Cambridge Educational Dialogue Research (CEDiR) Group. URL: http://www.academia.edu/37916282/A_Dialogue_About_Edu-

cational_Dialogue_Reflections_on_the_Field_and_the_Work_of_The_Cambridge_Ed ucational_Dialogue_Research_CEDiR_Group

Mashkin, N.A., Batyukova, V.E., Krokhina, J.A., Shagieva R.V., Chistyakov, A.A., \& Korzhuev, A.V. (2021). Traces of Aristotle in Martin Luther's theological anthropology. Konstantinove Listy 14(1), 88-99. ISSN: 1337-8740.

Mercer, N., Wegerif, R., \& Major, L. (2019). The Routledge International Handbook of Research on Dialogic Education. Routledge Handbooks Online. ISBN 9781138338517 https://doi.org/10.4324/9780429441677.

Pritchard, D. (2013). Epistemic Virtue and the Epistemology of Education. Journal of Philosophy of Education 47(2), pp. 236-247. ISSN: 2658-6762.

XLinguae, Volume 15 Issue 1, January 2022, ISSN 1337-8384, eISSN 2453-711X 
Rapanta, C., \& Macagno, F. (2019). Evaluation and promotion of argumentative reasoning among university students: The case of academic writing. Revista Lusofona de Educacao 45, 125-142. ISSN: 1645-7250.

Rapanta, C. (2019). Argumentation as critically oriented pedagogical dialogue. Informal Logic 39(1), 1-31. ISSN 2293-734X.

Rapanta, C. (2018). Teaching as Abductive Reasoning: The Role of Argumentation. Informal Logic 38(2), 293-311. ISSN 2293-734X.

Razumovskaya, M., Zaitseva, N.A., Larionova, A.A., Chudnovskiy, A.D., \& Breusova, E.A. (2018). Prospects for applying various forms of organizational integration to improve the quality of education. Astra Salvensis 6, 348-362. ISSN: 23441887.

Rodek, V. (2019). Learning and its Effectiveness in Students' Self-reflection. The New Educational Review 55, 112-120. ISSN: 1732-6729.

Rose, D. (2014). Analysing pedagogic discourse: an approach from genre and register. Functional Linguist 1(11), 1-32. ISSN 2196-419X.

Sabirov, I.T., Ponkratova, L.A., Gracheva, N.A., Kiselev, S.V., Zaitseva, N.A., Fatikhova, L.E., \& Chudnovskiy, A.D. (2015). The formation and development trends of the consulting market in Russia. Mediterranean Journal of Social Sciences 6(2S3), 188-195. ISSN: 2039-2117.

Searle, J.R. (2004). Mind: a brief introduction. Oxford: Oxford university press. ISBN: 0195157338.

Shirish, T.S. (2013). Research Methodology in Education. Lulu Publication. ISBN: 9781329647428.

Skidmore, D., \& Murakami, K. (2016). Dialogic Pedagogy: The Importance of Dialogue in Teaching and Learning. Bristol: Multilingual Matters. ISBN: 978-1-78309621-3.

Snaza N. (2018). Aleatory entanglements: (Post) Humanism, hospitality and attunement - A response to Hugo Letiche. Journal of Curriculum and Pedagogy 14, 256-272. ISSN: 15505170, 21568154.

Spitzer, M. (2014). Digital Technologies and Brain. Translated from German. Moscow: AST. ISBN: 978-5-17-079721-9.

Stubbs, M. (2007). Text, Discourse and Corpora: Theory and Analysis. London: Continuum. ISBN: 1441194851.

Tannen, D. (1999). The Argument Culture: changing the way we argue and debate. London: Virago. ISBN 10: 0860683710.

Tariqan, A.N. (2012). Teaching Critical Thinking: Practical Wisdom by bell hooks. Teaching Sociology 1, 182-183. ISSN: 0092-055X.

Tomasz, L. (2017). The research potential of educational theory: On the specific characteristics of the issues of education. Educational Philosophy and Theory 49(14), 1428-1440. ISSN 0013-1857.

Zenker, F. (2018). Introduction: Reasoning, Argumentation, and Critical Thinking Instruction. Topoi 37(1), 91-92. ISSN 1572-8749.

Words: 8327

Characters: 56310 (31,28 standard pages)

Prof. Andrey V. Korzhuev, Dr.

I.M. Sechenov First Moscow State Medical University (Sechenov University)

8 Trubetskaya Street,

119991 Moscow

Russia

akorjuev@mail.ru 
Senior Lecture Almira R. Bayanova, PhD.

Kazan (Volga region) Federal University

Mezhlauka 1

420111 Kazan

Russia

almira-djl@mail.ru

Assoc. Prof. Saule B. Dautova, Doctor of Philology

Abai Kazakh National Pedagogical University

Dostyk ave. 13

050010 Almaty

Republic of Kazakhstan

a730chn@mail.ru

Assoc. Prof. Svetlana V. Dmitrichenkova, PhD in Education

Peoples' Friendship University of Russia (RUDN University)

Mikluho-Maklaya Str., 6

117198 Moscow

Russia

sw.wl@mail.ru

Prof. Muslimat G. Akhmedova, Doctor of Philosophy

Financial University under the Government of the Russian Federation

Leningradsky Prospekt, 49

125993 Moscow

Russia

muslima11@rambler.ru 